\title{
Procesos de periurbanización y cambios en los modelos de ciudad
}

\section{Un estudio europeo de casos sobre sus causas y consecuencias}

\author{
Francisco Entrena Durán \\ Universidad de Granada. Departamento de Sociología \\ 18071 Granada \\ fentrena@ugr.es
}

\section{Resumen}

Los procesos de creciente periurbanización, característicos del mundo desarrollado actual, están suponiendo la progresiva expansión de modelos de ciudad desconcentrada, dispersa o difusa, lo que hace que cada vez sean más borrosas e imprecisas las fronteras físicas y sociales entre lo rural y lo urbano. En esta situación, se está experimentando un progresivo aumento de la importancia de las periferias urbanas y una mejora de la imagen de éstas, las cuales, de ser lugares de frecuente exclusión social y subdesarrollo durante la preponderancia de los modelos centralistas de ciudad, están pasando, en bastantes casos, a manifestar un significativo dinamismo socioeconómico. Este artículo, además de analizar los cambios y los nuevos modelos de ciudad derivados de los presentes procesos de periurbanización, trata de identificar algunas de las causas y consecuencias de tales procesos. Causas y consecuencias que se consideran, tanto a nivel general, como a través de la exposición de parte de los resultados de una investigación empírica llevada a cabo en diferentes áreas periurbanas de la Unión Europea. El trabajo concluye con unas reflexiones que se pretende sean útiles para encarar la generalidad de los retos que se les plantean a las actuales políticas reguladoras de las áreas de urbanización dispersa, en tanto que los procesos de periurbanización que dan lugar a las mismas, aunque originados o propulsados por causas o fuerzas diversas, suelen tener consecuencias socioeconómicas, ambientales y urbanísticas similares.

Palabras clave: periurbanización, ciudad dispersa, presión urbana, fronteras entre mundo rural y mundo urbano.

\section{Abstract. Periurbanization processes and changes in the models of city. An european cases study on their causes and consequences}

The processes of growing periurbanization, which are so characteristic in the current developed world, are giving rise to a progressive spread of diffuse or disperse models of city, what, in turn, is bringing with it that the geographic and social borders between the rural and urban ambits are more and more blurred and vague. In this situation, the urban peripheries are undergoing an increasing relevance, at the same time that their image is improving. These peripheries, from being traditionally places of frequent social exclusion and underdevelopment when the centralist models of city were preponderant, are nowadays showing often a significant socio-economic dynamism. The article, apart from analysing the changes and new models of city coming with the current periurbanization processes, attempts to identify some of the causes and consequences of such processes. Causes and 
consequences that are considered, both, from a general viewpoint and by presenting some of the results of an empirical research carried out in different periurban areas from the European Union. While being fuelled by diverse causes, periurbanization entails similar socio-economic, urban and environmental outcomes in all the analysed areas. So, the author concludes by reflecting on some of the common challenges which the policies have now in order to face suitably such outcomes.

Key words: periurbanization, disperse city, urban pressure, rural-urban borders.

\section{Sumario}

Introducción Algunas causas y consecuencias

De la dicotomía entre campo y ciudad a la creciente expansión de áreas periurbanas de urbanización dispersa

Los imprecisos límites físicos y socioeconómicos de las áreas periurbanas de las presentes formas de urbanización dispersa

Retos de las actuales políticas reguladoras de las áreas periurbanas

Referencias bibliográficas

Hacia la constitución de formas de ciudad difusa y sin confines

\section{Introducción}

Este trabajo se basa en la realización, entre 2001 y 2004, de un proyecto de investigación internacional europeo sobre Urban Pressure on Rural Areas: Mutations and Dynamics of Periurban Rural Processes, financiado por el 5० Programa Marco de la Comisión Europea. En este proyecto, cuyo acrónimo es NEWRUR y así será aludido a partir de ahora, han participado equipos investigadores de Francia, Inglaterra, Alemania y España. María del Río Lozano y Nieves Rodríguez Madrid han sido las dos investigadoras que, conjuntamente conmigo y en coordinación con los restantes equipos implicados en NEWRUR, han hecho las revisiones bibliográficas, los trabajos de documentación, la identificación y el estudio socioeconómico de las áreas periurbanas escogidas en España como casos para ser investigados en profundidad, las entrevistas ${ }^{1}$, el análisis de las mismas y la redacción de los informes preliminares en los que se basan muchas de las argumentaciones e ideas que aquí se exponen. En concreto, las áreas periurbanas seleccionadas, en cada uno de los países participantes en NEWRUR, para ser investigadas de manera comparativa, han sido las siguientes:

1. Durante la realización de NEWRUR, el equipo español hizo 108 entrevistas en profundidad, entre julio de 2002 y enero de 2004, a personas andaluzas interesadas o de alguna manera implicadas en los cambios socioeconómicos o problemas experimentados en las áreas periurbanas; especialmente, en las áreas de Granada y El Ejido seleccionadas. Así, las entrevistas fueron hechas a personas relacionadas con asuntos tales como la expansión residencial, la generación de empleo, la provisión de servicios o la mejora de los mismos, los impactos ambientales o la formulación y/o la implementación de las políticas relacionadas con la ordenación del territorio. 
1. En Francia: Annecy como área principal y Valence como área secundaria.

2. En Inglaterra: Norwich como área principal y Bedford y Cambridge como áreas secundarias.

3. En Alemania: Munich.

4. En España: Granada como área principal y El Ejido como área secundaria.

Los considerables aumentos demográficos experimentados en muchas ciudades del planeta durante la segunda parte del siglo XX han repercutido decisivamente en que los procesos de periurbanización vengan siendo, desde hace décadas, fenómenos mundiales con creciente extensión e influencia manifestados con especial intensidad en el contexto de la Unión Europea. Ello ha llevado a que se haya desarrollado una amplia literatura al respecto, cuyo análisis constituye una exigencia ineludible, en tanto que las diferentes perspectivas teóricas con referencia a la periurbanización constituyen distintas maneras de explicar los cambios y los nuevos modelos de ciudad de ella derivados, los cuales son examinados en este trabajo en los epígrafes titulados «De la dicotomía entre campo y ciudad a la creciente expansión de áreas periurbanas de urbanización dispersa", "Los imprecisos límites físicos y socioeconómicos de las áreas periurbanas» $\mathrm{y}$ «Hacia la constitución de formas de ciudad difusa y sin confines».

Posteriormente, se dedica un epígrafe a determinar algunas de las causas y consecuencias de las presentes formas de urbanización dispersa a que dan lugar los procesos de periurbanización. Causas y consecuencias que se analizan, tanto a nivel general, como a través de la exposición de parte de los resultados de la investigación empírica comparativa llevada a cabo en las diferentes áreas periurbanas europeas antes mencionadas. La finalidad de tomar en consideración estos cuatro casos concretos como objetos de investigación fue establecer y probar procedimientos adecuados para estudiar las trasformaciones y las nuevas formas de ciudad derivadas del fenómeno periurbano que luego puedan ser extrapolados a otros contextos similares. Para ello se identificaron los factores impulsores de tal fenómeno (es decir, sus causas) y se determinaron las consecuencias del mismo en términos de las transformaciones en el uso de la tierra, de la evolución de la agricultura, de los impactos sobre el medio; así como las modificaciones que todo esto acarrea en lo referente a la expansión residencial, el crecimiento de los servicios y en el aumento del empleo y la diversificación de las fuentes del mismo.

El artículo finaliza con unas reflexiones que se pretende sean apropiadas para afrontar los retos que tienen ante sí las actuales políticas reguladoras de las áreas de urbanización dispersa. Retos que pueden ser encarados de manera general, ya que los procesos de periurbanización que dan lugar a tales áreas, aunque originados o propulsados por causas o fuerzas diversas, suelen tener consecuencias similares sobre el medio, la agricultura, el empleo, los servicios, o en lo que se refiere a propiciar el crecimiento físico de la ciudad a través de la expansión residencial. 


\section{De la dicotomía entre campo y ciudad a la creciente expansión de áreas periurbanas de urbanización dispersa}

En primer lugar, en lo que respecta a la literatura relativa a la periurbanización, ésta se ha desarrollado sobremanera en un contexto en el que, en la mayor parte de los países del mundo avanzado, se ha experimentado una significativa revalorización del papel de las áreas metropolitanas, así como una intensificación de su crecimiento y expansión. Todo ello está dando lugar a cambios urbanos de tal magnitud que diversos autores han considerado necesario proponer nuevas denominaciones para aludir a estas manifestaciones emergentes de ciudad, cuyas características son cada vez más distintas de las formas compactas de ciudad ${ }^{2}$. Es en este contexto en el que hay autores que hablan de la ciudad desconcentrada o dispersa, la cual se caracteriza por la propagación espacial de la población urbana, entendiendo por ésta la que no está funcionalmente vinculada a las actividades propias de las áreas rurales, es decir, la población que reside en las áreas rurales y que no se encuentra ocupada en las tareas agrícolas (Ferrás, 2000, p. 6).

A medida que se han ido desarrollando las tendencias hacia la urbanización dispersa, se ha ido haciendo más borrosa la separación entre el campo y la ciudad, si es que alguna vez existió esta separación. Simultáneamente, las transformaciones económicas y tecnológicas inherentes a ello han provocado la integración funcional y física del espacio, hasta tal punto que las actividades económicas y las formas de vida urbanas se han esparcido casi por la totalidad de los territorios de los países europeos. Como consecuencia de ello, cada vez son menos acentuadas las diferencias entre la realidad rural y la urbana, al mismo tiempo que se experimenta una creciente imbricación y relación entre ambas realidades.

Desde el punto de vista teórico, hay diferentes aproximaciones a las presentes formas de urbanización dispersa. De este modo, aunque ésta es una consecuencia de la creciente expansión espacial del crecimiento de los centros urbanos, tal crecimiento ha sido asociado diferencialmente a conceptos o procesos como el de suburbanización (en las literaturas anglosajona, española e italiana), rururbanización y periurbanización (en las literaturas francesa y española). En cambio, en Norteamérica (y también en parte de Europa), se ha hablado preferentemente de contraurbanización (Dematteis, 1998, p. 17). Asimismo, mientras que algunos consideran la urbanización dispersa como la continuación de la suburbanización, otros asumen como pertinente su tipificación como un fenómeno totalmente nuevo (Arroyo, 2001, p. 4).

Sin entrar a analizar aquí en detalle las causas de esta diversidad de interpretaciones y denominaciones, se podría afirmar que muy probablemente ello

2. Entre tales denominaciones, están las siguientes: «ciudad informacional» (Castells, 1989), "ciudad difusa» (Indovina, 1990), «ciudad global» (Sassen, 1991), "metápolis» (Ascher, 1995), «ciudad postmoderna» (Amendola, 1997), «metrópolis desbordada» (Geddes, 1997), "ciudad reticular» (Dematteis, 1998), "postmetrópolis» (Soja, 2000), "ciudad dispersa» (Monclús, 1998). 
está asociado a la escala con la que se mira a la realidad y al país y/o a la ciudad donde se genera la reflexión acerca del crecimiento de la urbanización dispersa, la cual manifiesta en cada situación unas singularidades específicas (Monclús, 1998, p. 8-9). En cualquier caso, más allá de estas singularidades, la generalidad de los recientes procesos de urbanización dispersa (y de consiguiente expansión del fenómeno periurbano) está dando lugar a la aparición de unas periferias urbanas muy diferentes de aquéllas que se habían formado en Europa desde la Revolución Industrial hasta la década de 1960 (Dematteis, 1998, p. 17).

En lo que se refiere a los casos concretos de los países estudiados en NEWRUR, las nuevas formas de urbanización dispersa se manifiestan en que en todos ellos se ha observado una progresiva evolución hacia una cada vez mayor indefinición de las fronteras socioeconómicas, culturales y físicas entre el ámbito rural y el urbano.

Por consiguiente, los espacios periurbanos se manifiestan como unas zonas en transición entre la ciudad y el campo, en las que, en consecuencia, se mezclan actividades urbanas y agrícolas que compiten por el uso del mismo suelo. Esto hace que la mayoría de los autores que estudian los espacios periurbanos coincidan en concebirlos como unos espacios multifuncionales que están sometidos a grandes y rápidas transformaciones y cuyo dinamismo está, en muy gran medida, determinado desde la ciudad ${ }^{3}$.

En esta situación, el desarrollo de los espacios rurales (sean éstos periurbanos o no) ha se basarse en la cooperación, la colaboración y la complementariedad urbano-rural, en contraste con la tradicional dicotomía entre campo y ciudad (Crecente, Miranda, Cancela y Marey, 2001). Todo ello asentado en la presuposición de que el desarrollo de las áreas periurbanas se verá fuertemente influenciado por la integración de las mismas en una red de ciudades (policentrismo) o por su vinculación funcional y socioeconómica con determinadas ciudades cabeceras comarcales, en las que se concentran los servicios y los equipamientos para la población de su área de influencia.

Esto acontece cuando muchos espacios rurales, más o menos influenciados por las ciudades, tienden a dejar de estar destinados básicamente a la producción agraria, a la vez que tiene lugar una progresiva urbanización de tales espacios, en tanto que éstos adquieren un papel cada vez más importante como ámbitos demandados por un número creciente de los habitantes de las urbes para satisfacer en ellos sus necesidades y anhelos de ocio, de descanso o de esa calidad de vida y de relación armónica con la naturaleza que no encuentran en sus congestionados y agitados escenarios cotidianos de residencia y de trabajo. Se explica, de este modo, que la preocupación por las cuestiones ambientales y por el uso duradero y sostenible de los recursos naturales constituya en los países avanzados de población mayoritariamente urbana uno de los temas

3. Una muestra de esta coincidencia entre la generalidad de los autores puede ser el título del IV Coloquio Hispano-Portugués de Estudios Rurales, celebrado en Santiago de Compostela entre el 7 y el 8 de junio de 2001. Dicho título fue: «La multifuncionalidad de los espacios rurales de la península Ibérica». 
de más debate y estudio. En tales países, la ordenación del territorio, entendida como política (económica, social, cultural y ambiental), práctica administrativa y disciplina científica, es una expresión frecuentemente utilizada. En particular, en lo que respecta a los países avanzados de nuestro entorno europeo más inmediato, el carácter democrático, global, funcional y prospectivo que se atribuye a la ordenación del territorio pretende la integración de soluciones técnicas e institucionales con la participación de la población.

En lo que se refiere a los autores que se ocupan de la dimensión ambiental de las políticas de ordenación del territorio, específicamente, en el caso español, cabe mencionar a Paniagua (1997), Garrido (1998), Sevilla-Guzmán y López Calvo (1993) e Izcara Palacios (1999). En cuanto a los que adoptan una actitud claramente comprometida con la ordenación de los territorios periurbanos, se menciona aquí el caso de López, Crecente y Fra (2001), para quienes las peculiaridades históricas y culturales de esos territorios deben ser preservadas, protegidas y promovidas. Así, según dichos autores, es muy importante el desarrollo de iniciativas comunitarias para la resolución de los problemas específicos del mundo rural. Para ello, entre otras diversas cuestiones, hay que tener en cuenta los criterios para el desarrollo espacial que aparecen reflejados en The Study Programme on European Spatial Planning (ESDP) (European Commision, 1999), a saber: la posición geográfica (la localización espacial de una cierta zona periurbana), la resistencia económica (la relativa relevancia económica de esa zona periurbana con respecto a otras), las ventajas naturales (la importancia, sensibilidad, extensión o peculiaridad de los ecosistemas y otras áreas naturales), las ventajas culturales (las características del paisaje y los bienes culturales antiguos y modernos), la integración social (el nivel de interacción entre los grupos sociales en cada zona y entre diferentes zonas), la presión sobre el uso de la tierra (la probabilidad de conflictos de intereses entre diferentes tipos de usos del suelo). Con respecto a este último punto, hay que tener en cuenta que la presión urbana que se experimenta en las áreas periurbanas tiene como efecto la reducción de la disponibilidad de tierras y, en consecuencia, el aumento del precio de las mismas (Hernández Montesinos, 2001). Asimismo, el crecimiento del tejido urbano tiende a causar la retirada de la agricultura y a favorecer la aparición de tierras abandonadas.

La progresiva multifuncionalidad socioeconómica de los espacios rurales está haciendo posible que, a pesar de que persista el proceso de paulatino descenso de la población agraria iniciado en España en la década de 1960, sea un hecho evidente, sin embargo, que no sólo las salidas de población del medio rural parecen no ser tan intensas como eran hace unas décadas, sino que en algunas situaciones, como es el caso de esos espacios rurales sometidos a los efectos de procesos de periurbanización más o menos intensos, se puede hablar incluso de aumento de las migraciones hacia ellos. Se trata de una muestra de la ya antes referida contraurbanización o urbanización dispersa (Berry, 1976), la cual, a su vez, puede ser considerada como un fenómeno característico de la llamada «sociedad postindustrial» (Bell, 1976; Touraine, 1980). Según Bell y Touraine, entre las características básicas de la sociedad postindustrial pueden destacar- 
se las siguientes: a) el incremento de la independencia entre la producción y la fuerza de trabajo, así como la utilización creciente de la tecnología en los procesos productivos; b) la renovación de ideologías, que ahora se centran, entre otros aspectos, en el consumo, en el sentimiento de autorrealización y en la búsqueda de una mayor calidad ambiental.

Pues bien, las tendencias hacia la urbanización dispersa y a la consiguiente periurbanización de los espacios rurales se sitúan en un contexto en el que la gran ciudad, preferida para vivir y trabajar en la época industrial, ha pasado a ser en la sociedad postindustrial un medio caro, y las economías de aglomeración se convierten en deseconomías. Además, lo urbano es a menudo percibido como un espacio insalubre que impide y dificulta los avances en la calidad de vida buscados por una, cada vez más amplia, franja de la población de las grandes y medianas ciudades de los países avanzados.

Según Antonio Font (1997), las presentes tendencias dan lugar a procesos de descentralización de las actividades y de la población, es decir, lo que aquí se viene llamando "contraurbanización» o "urbanización dispersa». Los teóricos de la economía y de la geografía regional, sobre todo los anglosajones (Berry, 1976; Fielding, 1982; Berg y otros, 1982), se han ocupado del estudio de tales procesos, los cuales, en realidad, se vienen experimentando en las sociedades occidentales industriales más avanzadas desde la década de 1970 y se están extendiendo, desde hace algún tiempo, en los sistemas urbanos y en los territorios del arco mediterráneo noroccidental. Siguiendo a Dematteis (1995), Font considera que en la constitución del espacio urbano se está produciendo el tránsito «del aglomerado a la red». Un tránsito en el que la centralidad significa pertenencia a alguna de las diversas redes de flujos y de relaciones de geometría variable, y en el que la localización de las actividades se produce, de manera individual y fragmentaria, en un territorio cada vez más autoorganizado e interdependiente. Ello, a su vez, se traduce en procesos de ocupación del suelo de carácter disperso.

Estas formas de ciudad dispersa o de "campo urbanizado» aparecen como un nuevo tipo de ciudad que nace de la crisis de la ciudad precedente. En los actuales procesos de expansión del territorio urbano, y por consiguiente de periurbanización, se manifiestan dos tendencias aparentemente opuestas o contradictorias entre sí, pero que en realidad son complementarias. Se trata, por un lado, de la tendencia, derivada de los procesos generales de globalización que afectan a los sistemas productivos, a la homogeneización de los comportamientos, de la forma de los artefactos, etc., la cual a observadores poco atentos puede hacer creer que las arquitecturas, las ciudades o los territorios son iguales. En el lado opuesto, vemos la tendencia hacia la afirmación de la especificidad y de la diferencia, del decisivo papel de lo contingente o de lo local como mecanismo de reacción y de defensa, pero también de definición y de afirmación de la singularidad y la identidad ante un mundo aparentemente cada vez más estandarizado.

Bajo estas premisas, Font lleva a cabo un intento de clasificación de los «territorios metropolitanos» y de los procesos de periurbanización que afectan 
a Barcelona, como resultado del cual establece una tipología que puede resultar especialmente significativa para aquéllos que pretenden aproximarse metodológicamente al fenómeno de la periurbanización. Así, dichos territorios periurbanos se manifiestan, ya como paisajes de baja densidad (los desagregados, los asentamientos dispersos), ya como escenarios en red (los elementos arteriales, los enclaves o los nodos). Los elementos propuestos en dicha tipología son descritos de la forma siguiente:

1. Aglomerados, es decir, asentamientos urbanos cuya característica principal es la continuidad de sus tramas, su relativa densidad y la mezcla de usos. Se trata de asentamientos de formación histórica o reciente que albergan los servicios y las actividades que se identifican con la centralidad.

2. Extensiones de las tramas urbanas por prolongación de sus mallas viarias, generalmente de carácter más monofuncional (residencial, industrial, etc.), y que por su relativa posición central están también sometidas a procesos recientes de densificación y transformación.

3. Hilos o filamentos, es decir, formaciones lineales a lo largo de infraestructuras viarias históricas (carreteras o caminos) o de elementos geográficos singulares (ríos, elementos orográficos, etc.). En su evolución, producen la soldadura entre asentamientos próximos y dan lugar a sistemas urbanos conurbados.

4. Desagregados, o sea, asentamientos en forma arbórea o en paquetes más o menos cerrados sobre topografías diversas, de carácter predominantemente residencial, aunque sean frecuentes también en el uso industrial y de almacenamiento en la segunda y tercera coronas metropolitanas.

5. Asentamientos dispersos, producidos como resultado de la ocupación individualizada del territorio rústico según una lógica autoorganizativa y sin las características de marginalidad o de autoconstrucción que fueron significativas en épocas anteriores.

6. Elementos arteriales. Se trata de las fibras o canales de comunicación o movilidad, que representan fundamentalmente las infraestructuras viarias y de transporte, y las de los sistemas energéticos y de telecomunicaciones, cada vez más relevantes para la organización territorial.

7. Enclaves o nodos, integrados por edificios o agrupaciones de edificios e instalaciones, situados en puntos estratégicos del territorio (enlaces de autopistas, intercambiadores de transporte, etc.), de máxima accesibilidad y/o significación metropolitana. Son los «nuevos lugares centrales».

Las tendencias actuales apuntan, pues, hacia una creciente revalorización de la realidad y de las imágenes de las áreas periurbanas o periferias urbanas. Contrariamente a esto, como señala Giuseppe Dematteis (1998), las periferias urbanas han sido en el pasado, con frecuencia, vistas como unos espacios cuyas cualidades nunca podían alcanzar a las del centro, aunque se intentaba hacerlo continuamente en un empeño inútil. Por si eso no bastara, en muchos casos las periferias de las grandes ciudades se han concebido como espacios donde 
las patologías urbanas y las desvalorizaciones eran máximas: la degradación física y social, la marginalidad, la exclusión, la desviación. Esta imagen negativa de las periferias urbanas derivaba de una concepción centralista de la ciudad que ya no tiene sentido en el presente contexto de creciente globalización, en el que las ciudades están sometidas a importantes fuerzas centrífugas (Bagnasco y Le Galés, 2000, p. 3). De ahí, la creciente preponderancia social y económica que durante las últimas décadas vienen adquiriendo en el mundo desarrollado las áreas periurbanas. En este contexto, sin negar la importancia que tiene para el dinamismo de esas áreas la existencia de vínculos privilegiados entre ellas y las ciudades centrales, también son muy importantes en el desarrollo de las zonas periurbanas las relaciones que éstas mantienen con los grandes centros urbanos y de decisión socioeconómica a escala global. Por ejemplo, el desarrollo de determinadas poblaciones turísticas importantes de la zona de la Costa del Sol cercanas a Málaga, además de por su relación periurbana con esta ciudad, no podría ser explicado sin tomar en cuenta también el amplio conocimiento que existe en el ámbito internacional de tal zona, lo que, a su vez, la hace formar parte de una red de relaciones y de flujos de personas, ideas y mercancías que opera prácticamente a escala mundial (Castells, 1996).

\section{Los imprecisos límites físicos y socioeconómicos de las áreas periurbanas}

Como ya se ha dicho antes, cada vez se ha ido haciendo más indefinida la frontera entre el campo y la ciudad. Esta indefinición se patentiza especialmente en las áreas periurbanas, una de cuyas principales características es su naturaleza difusa. Según Manuel Castells, en tales áreas "se incluyen, en discontinuidad espacial, zonas construidas de diversa densidad, espacios abiertos, actividades agrícolas, reservas naturales, extensiones residenciales y concentraciones de servicios y actividades industriales, repartidos a lo largo de ejes de transporte constituidos por autopistas y sistemas de transporte público. No existe una verdadera división en zonas, ya que los lugares de trabajo y las áreas residenciales y comerciales están dispersos en varias direcciones. Es más, aunque estas regiones suelen estar centradas en torno a una gran ciudad central, los centros urbanos menores quedan gradualmente absorbidos en redes intrametropolitanas. Se forman nuevos nodos constantemente» (Castells, 2001, p. 258-259).

En las áreas periurbanas, es posible observar una vinculación de los límites de la región urbana con espacios predominantemente rurales donde viven personas que trabajan en la ciudad (Precedo Ledo, 1996, 238 y s.). Pero la expresión "región urbana» es polisémica e imprecisa. Unas veces se aplica para designar el espacio regional organizado por una ciudad, según el concepto de región nodal o polarizada, otras para denominar un área metropolitana de grandes dimensiones, y, también, aunque en menor medida, dicha expresión se emplea para describir una región urbanizada. Este último es precisamente el sentido que nos interesa aquí. Para Precedo Ledo (1988, p. 90), una región urbana o urbanizada es una compleja estructura interurbana, formada por una malla o red de asentamientos urbanos dispersos, es decir, una especie de nebu- 
losa urbana (pero suficientemente densa e incluyendo las áreas rururbanas) que posee características sociales y económicas propiamente urbanas, y que funcionalmente está constituida como un espacio unitario.

En el presente trabajo se considera al área periurbana y la rururbana como partes integrantes de la región urbana o urbanizada, tal como ésta es entendida por Precedo Ledo (1988). Cuando aquí se afirma que el área periurbana tiene una "naturaleza difusa» no se hace referencia sólo al carácter indefinido de sus fronteras físicas o geográficas, sino que también se alude a lo socioeconómico. En otras palabras, los límites de lo periurbano son imprecisos, no sólo porque física o geográficamente sea difícil establecer con nitidez una separación clara entre la ciudad y sus zonas periurbanas próximas, o entre éstas y lo que se considera como rural, sino también porque en tales zonas suele haber formas de sociedad cuyas características sociales y económicas se encuentran en proceso de cambio y de redefinición, por lo que no están claramente fijadas, manifestándose como una especie de construcciones híbridas que están a caballo entre lo urbano y lo rural. A este respecto, coincido con Carter, quien se vale del concepto de la «franja rural-urbana» para hacer referencia a estas áreas intermedias (1987, p. 431). Se trata de un efecto de la expansión y la dispersión de la ciudad que da lugar a unos espacios sociales específicos sólo parcialmente asimilados por el complejo crecimiento urbano. Estos espacios conservan bastantes de los rasgos típicos de ámbito rural en el que muchos de sus habitantes viven de hecho, pero sin que ello signifique que socioeconómicamente dependan de ese ámbito. Se trata de una forma de ocupación del territorio que no es ni propiamente rural ni tampoco urbana. Una de sus características más destacadas es la pluriactividad de sus habitantes. En suma, el proceso de dispersión que suele caracterizar el crecimiento de las actuales ciudades ha dado lugar a la constitución de unas áreas periurbanas, cuyos límites espaciales, peculiaridades socioeconómicas y formas de vida tienen un carácter más o menos mixto o rururbano (Zárate, 1984, p. 100).

La gran expansión de las áreas periurbanas en Europa es una consecuencia del crecimiento por aglutinación de sus ciudades, anexionándose los núcleos de población situados en su entorno. Esta expansión, iniciada en las ciudades americanas en el período de entreguerras, sobre todo entre 1936 y 1940 , comenzó a manifestarse en los países europeos al final de la Segunda Guerra Mundial. Desde que en 1940 se acuñara, en los Estados Unidos, el concepto de áreas metropolitanas para tratar de dar respuesta administrativa a este nuevo hecho geográfico, se ha hecho patente la diversidad de significaciones atribuidas a este concepto, como diversas son las realidades urbanas a las que el mismo ha sido aplicado y numerosos los autores que lo han usado (Frey y Zimmer, 2001, p. 26-31). Por ejemplo, en el ámbito europeo, Zárate conceptúa las áreas metropolitanas como áreas rururbanas debido a sus características híbridas entre el campo y la ciudad. La formación de tales áreas se ha desarrollado en las diferentes ciudades de acuerdo con uno o varios de los tres modelos siguientes: 
1. Desarrollo discontinuo. La franja rururbana ha surgido en torno a la ciudad central de manera regular dando origen a un área de baja densidad de población.

2. Desarrollo radial. El crecimiento ha tenido lugar a lo largo de las principales vías de acceso y de forma segmentada.

3. Desarrollo a saltos. La franja rururbana se compone de núcleos de usos de suelo urbano en medio de territorios cuya función es exclusivamente rural (Zárate, 1984, p. 104).

También se refleja la compleja e híbrida naturaleza de las áreas metropolitanas en la aproximación que Francisco Pellicer (1998) hace a las mismas. Así, según Pellicer, en tales áreas se yuxtaponen y coparticipan en un complejo sistema de interacciones los tres siguientes tipos de espacios periurbanos:

1. Espacios naturales. Por ejemplo, con zonas húmedas y riberas fluviales de elevada productividad biológica y gran potencial como espacios recreativos y de contacto con la naturaleza: albuferas, galachos o meandros abandonados, sotos y cauces fluviales, marismas, saladares, sistemas de dunas.

2. Espacios rurales. A este respecto, quizá sea la huerta la expresión cultural más valiosa de las profundas relaciones entre la biosfera y la antroposfera en el caso del mundo tradicional mediterráneo.

3. Espacios urbanos. Barrios periféricos, nuevas urbanizaciones de residencia habitual o secundaria, instalaciones turísticas, grandes infraestructuras urbanas y polígonos industriales, entre otras muchas manifestaciones.

De lo antedicho, se desprende que los espacios periurbanos son unos espacios que están en continua crisis, que deben responder a numerosas funciones. Por lo general, reciben todo aquello que arroja la ciudad o no tiene cabida en ella y absorben funciones que, en determinados casos, requieren condiciones de cierto alejamiento, tamaño suficiente y menor precio del suelo (Sancho Martí, 1989). El uso tradicional de los espacios periurbanos ha experimentado en la generalidad de los países europeos drásticos cambios, debidos a la desvalorización en términos económicos de las actividades agrícolas, a la fuerte demanda de tierra para una expansión urbana altamente consumidora de suelo (extensas urbanizaciones de desarrollo horizontal, segundas residencias, equipamientos e infraestructuras diversas, vías de comunicación y transporte, etc.), a la gran capacidad técnica existente hoy para la transformación de tales espacios (encauzamientos, puentes, grandes infraestructuras...), a la enorme producción de desechos, a la demanda masiva de materiales para la construcción, y a la presión de los ciudadanos, que reclaman lugares de ocio y de esparcimiento públicos y privados. Especialmente, desde el punto de vista medioambiental, los espacios periurbanos son unos espacios desarticulados, debido al uso arbitrario que de ellos se ha hecho, sometidos muchas veces a intereses privados escudados en la inercia permisiva de las administraciones, cuando no en la complicidad manifiesta de éstas con tales intereses (Sancho Martí, 1989). 
Ante el creciente deterioro que están sufriendo muchos de los espacios periurbanos, sobre todo como consecuencia de intensos y a menudo descontrolados procesos de urbanización, Pellicer (1998) plantea la necesidad del restablecimiento de relaciones equilibradas entre la ciudad y su entorno. Esto, en su opinión, exige restaurar los espacios periurbanos degradados, revitalizarlos ecológica, cultural y económicamente para satisfacer las nuevas demandas sociales de calidad de vida. A este respecto, cuestiones centrales para la mejora de la calidad de vida de los ciudadanos en los entornos locales periurbanos son las siguientes:

1. Control de la expansión física de los centros urbanos.

2. Adecuada regulación de su heterogeneidad funcional y social, sobre todo donde existe amenaza de exclusión social.

3. Efectiva y eficiente gestión de su ecosistema.

4. Mejora de la accesibilidad y del transporte, recurriendo para ello a opciones respetuosas con el medio ambiente.

5. Conservación y desarrollo de su herencia natural y cultural.

Estos puntos previos derivan de los objetivos del ESDP, los cuales, a su vez, están orientados por la triple meta de: conseguir la cohesión social y económica (especialmente, en lo que respecta a la preocupación de la Unión Europea por el desarrollo económico y la reducción del desempleo), conservar los recursos naturales y el patrimonio cultural, y lograr una más equilibrada competitividad de los territorios europeos (European Commission, 1999, p. 11).

Para la materialización de todos estos objetivos, se requiere una planificación urbana mucho más efectiva y respetuosa con las normativas establecidas y con el entorno natural de lo que hasta ahora está siéndolo. No obstante, lejos de tenderse hacia ello, por el momento, en varios países europeos, entre los que pueden incluirse los casos de Alemania y España estudiados en el proyecto NEWRUR, se está produciendo un desmesurado y descontrolado crecimiento de la urbanización. Como consecuencia, en las áreas periurbanas investigadas en tales países está teniendo lugar una progresiva pérdida de la extensión de tierra dedicada a las tareas agrícolas, con la excepción del caso de El Ejido, en el que la urbanización va paralela a la ampliación de esa tierra y es debida precisamente a la intensificación de la moderna agricultura de invernadero.

En la actual situación, de paulatino descenso de la importancia y la extensión de la agricultura periurbana, el mantenimiento de ésta será viable en la medida en que se logre revalorizar los espacios destinados ella. Para esto, es preciso aumentar, cada vez más, la conciencia acerca de las múltiples funciones de tales espacios y de su contribución al funcionamiento del ecosistema metropolitano, en cuya gestión hay que tener en cuenta las necesidades reales y la voluntad de los actores sociales que en él viven, así como el papel decisivo que éstos pueden desempeñar en la definición y puesta en marcha de las estrategias socioculturales, económicas y ambientales relacionadas con dicha gestión (Bryant, 1995). Tales estrategias han de encaminarse a que las funciones de 
los espacios naturales y rurales periurbanos no sólo se limiten a sus usos agrarios, sino que también éstos puedan desarrollar un papel fundamental como soportes de las numerosas actividades recreativas, deportivas y educativas demandadas por la nueva sociedad urbana, y como factores de paisaje de calidad, abierto y natural, en contraposición al cerrado, artificial y tenso espacio físico y social de la ciudad (Gómez Orea, 1995).

\section{Hacia la constitución de formas de ciudad difusa y sin confines}

Los que Giuseppe Dematteis (1998, p. 17) califica como recientes procesos de periurbanización y de difusión reticular de la ciudad acontecen en Europa en una situación en la que, desde una perspectiva territorial, estamos presenciando procesos generales hacia el reforzamiento de la competencia entre los territorios y el fortalecimiento del papel de las metrópolis. Las relaciones de los individuos con el territorio y la organización socioterritorial están pasando de tener lugar en zonas concretas a desarrollarse a través de redes cada vez más extensas y globalizadas. Esto confiere un papel particularmente importante a las ciudades como nodos de una red que se extiende sobre la base de un sistema mundial de ciudades, con una jerarquización que tendrá en su cima unas pocas grandes metrópolis mundiales y un conjunto de ciudades internacionales y regionales que articularán las grandes relaciones mundiales (Sánchez, 1998). Pero, como acertadamente señala Dematteis (1998), a la vez que tiene lugar todo esto, se está experimentando un progresivo fortalecimiento de la importancia de las nuevas periferias urbanas. Esto sucede precisamente cuando los dos caminos históricos principales de la suburbanización occidental europea (el anglosajón y el latino-mediterráneo) acaban convergiendo en un único modelo, el cual, bajo una diversidad de denominaciones ("ciudad difusa», «periurbanización», "ciudad reticular»), presenta en toda Europa caracteres comunes e innovadores.

Las nuevas periferias urbanas desarrolladas en las décadas de 1980 y 1990 sugieren la idea de una especie de "ciudad sin centro». Se trata de un modelo de urbe que se basa en la interconexión física y funcional de unos lugares y unos sistemas urbanos que tratan de conservar y potenciar su propia identidad, ya que ven en ello un recurso que pueden hacer valer en la competición global. La imagen de las nuevas periferias es entonces compleja: en la escala macro aparece una única gran estructura difusora en forma de red, mientras que, en la escala micro, cada nodo de esta red revela caracteres específicos, identidades particulares y principios de organización espacial característicos.

Todos estos cambios, que se enmarcan en el tránsito del modelo económico que se conoce como el fordismo a la fase posfordista (Bagnasco y Le Galés, 2000, p. 12), tienen consecuencias notables en el modo de concebir las políticas urbanas y la propia planificación urbanística (Lever, 2001). Aunque este aspecto se aparta del tema aquí abordado, no se puede dejar de hacer referencia a él, ya que el gobierno de las nuevas periferias citadanas es probable- 
mente una de las cuestiones clave para decidir el futuro urbano de Europa y del mundo en general. Así, el paso del fordismo al posfordismo, no sólo ha conllevado un cambio de imagen de las ciudades europeas, las cuales son hoy mucho más difíciles de definir y se caracterizan por una mayor heterogeneidad y polarización internas, sino que el marco de progresiva globalización, en el que ha tenido lugar ese paso, ha vuelto ineficaz el control territorial directo por parte de la Administración pública, en tanto que estructura jerárquica centralizada a través de la cual se había ejercido tradicionalmente dicho control, o sea, desde el Estado hasta el municipio. A diferencia de esto, en la actualidad los actores socioeconómicos locales cada vez tienen más posibilidades de establecer entre sí relaciones horizontales directas que traspasan cualquier confín territorial concreto, lo cual opera en detrimento del funcionamiento territorial centralizado de las formas tradicionales de control.

Durante la década de 1950, el patrón general de migración en los países de Europa Occidental estuvo caracterizado por la correlación entre la inmigración y el tamaño de los centros de población (Fielding, 1982). Esta tendencia se vio modificada hacia la década de 1970, durante la cual dicha correlación fue invertida, de tal forma que los centros principales experimentaron una disminución de la inmigración, a la vez que ésta aumentaba en las poblaciones pequeñas y medianas. Se empezaba así a producir el progresivo paso del modelo de urbanización compacta, entonces dominante, hacia el fenómeno que está siendo conceptuado aquí como contraurbanización o extensión de formas de urbanización difusa.

La dispersión urbana inherente a la paulatina expansión de modelos difusos de ciudad se caracteriza, fundamentalmente, por el predominio de bajas densidades poblacionales o de construcciones de diversos tipos, tales como industrias, universidades o centros comerciales fuertemente vinculadas a infraestructuras viales adecuadas y por la presencia recurrente de espacios libres o que no disponen de edificaciones (Monclús, 1998, p. 7). La imagen de esta urbanización difusa es reflejada muy bien por Ferrás cuando señala que «estamos asistiendo a la explosión de la ciudad sobre la región, por la cual las actividades económicas, la población y la vivienda se expanden y fluyen hacia las áreas rurales próximas a la ciudad» $(2000$, p. 2). Una explosión de la ciudad a la que subyace un cambio de sentido de los flujos migratorios, los cuales pasan a ser de campo a ciudad, a ciudad a campo predominantemente.

Para entender las presentes tendencias hacia la extensión de formas de urbanización dispersa sin unos claros confines, es conveniente tomar en cuenta, de un lado, un criterio estructural, asociado a una modalidad de proceso de descentralización que muestra mayores tasas de crecimiento en unidades urbanas intermedias o relativamente pequeñas y, de otro lado, un criterio espacial que está asociado a la redistribución de la población y del trabajo en un contexto interregional más allá de las zonas de influencia habituales de las grandes ciudades (Butzin, 1988, p. 6). Según Dematteis (1998, p. 20), la dispersión de la ciudad está fuertemente vinculada al ciclo de vida urbano, que presenta en orden los estadios de urbanización, suburbanización, desurbanización y reur- 
banización. En este sentido, podemos asumir complementariamente también que los mercados del suelo y de la vivienda, lo mismo que la posibilidad de prestación de servicios públicos básicos, se erigen en reguladores y catalizadores de la desconcentración urbana (Nello, 1998, p. 49). Sin embargo, los casos analizados en el proyecto NEWRUR muestran que esto último no suele traducirse también en lo que podría conceptuarse como una desconcentración del desarrollo, en una distribución relativamente homogénea del mismo por la generalidad del área periurbana. Así, aunque el espíritu del ESDP aboga por la idea de la consecución de un desarrollo policéntrico, lo cierto es que durante la realización de dicho proyecto hemos visto que la desconcentración de la inversión, con respecto a los centros urbanos de los que dependen las áreas periurbanas investigadas, sólo se produce en algunos casos y con un limitado efecto.

\section{Algunas causas y consecuencias de las presentes formas de urbanización dispersa}

Desde un punto de vista general, las entrevistas desarrolladas en el curso de la realización de NEWRUR mostraron que las personas que optan por escoger las áreas periurbanas de urbanización difusa para vivir en ellas hacen esto motivadas por causas muy diversas, las cuales pueden ser desde el tratar de residir en un ambiente más tranquilo y menos ajetreado hasta la búsqueda de ese reencuentro con la naturaleza que es característico de algunas posturas ecologistas o, simplemente, poder acceder a una vivienda más barata. En cualquier caso, independientemente de cuáles sean tales razones, lo cierto es que, en el curso de dichas investigaciones, se pudo demostrar como las actuales formas de urbanización dispersa se producen porque las condiciones socioeconómicas y las normativas políticas hacen posible que exista suelo disponible y que, para determinados grupos sociales, sea más rentable económicamente el uso urbano de ese suelo que dejarlo como espacio agrícola o como zona verde. Asimismo, todo esto sucede porque hay una considerable parte de la población con unos hábitos culturales o de vida y unos niveles de ingresos que les permiten o predisponen a llevar a cabo asentamientos de tipo disperso y desconcentrado. A todo ello hay que añadir los avances en los medios de locomoción que han tenido lugar en los últimos años, los cuales han acrecentado considerablemente la capacidad de movilidad de los ciudadanos, que ahora disponen de mejores infraestructuras viarias y tienen más recursos económicos y medios de transporte públicos y/o privados para desplazarse diariamente, a lo largo de distancias considerablemente mayores que en el pasado, desde su lugar de residencia hasta el de trabajo y viceversa, así como más oportunidades socioeconómicas para realizar excursiones periódicas hacia medios rurales relativamente alejados durante los fines de semana y períodos vacacionales. Se ha favorecido, de esta forma, una creciente desconcentración de lo urbano, que cada vez se manifiesta más como una realidad expandida por territorios progresivamente más extensos. 
Pero las antedichas son sólo algunas de las razones por las que las ciudades tienden a dispersarse. Razones que son de muy variada índole, pero que puede hacerse referencia conjuntamente a ellas como una amalgama de factores entre los que destacan los siguientes: los procesos de cambios socioeconómicos en los que se encuentran inmersas las sociedades avanzadas actuales, la mejora de las posibilidades de transporte y de comunicación, así como la búsqueda de un confort, una tranquilidad y una calidad de vida que para muchos ya no propician los congestionados, y a menudo contaminados, entornos urbanos compactos. A este respecto, como acertadamente señala Dematteis, las nuevas periferias periurbanas «son el resultado de profundos cambios en las estructuras territoriales urbanas (desurbanización, contraurbanización), en las tecnologías de la comunicación y de la información (telemática), en la organización y en la regulación social que han transformado a los países industrializados a partir de finales de la década de 1960" (1998, p. 17). Uno de los efectos más sobresalientes de todas estas transformaciones socioeconómicas es la creciente expansión y dispersión de las ciudades, cuyos límites físicos (la existencia de murallas) y administrativos (jurídicos) comenzaron a sobrepasarse en Europa Occidental a partir de la Revolución Francesa (Nello, 1998, p. 36-38). Con frecuencia, la trasgresión de los límites físicos fue una consecuencia de la falta de espacio, del hacinamiento y de las muy poco saludables condiciones de vida de la población de las amuralladas ciudades del Antiguo Régimen. Esta circunstancia, unida a los efectos de la Revolución Industrial y del considerable incremento demográfico que tuvieron lugar en el siglo XIX, contribuyó a propiciar que las ciudades europeas comenzaran a crecer, al principio de manera concentrada, para, posteriormente, continuar con los procesos de dispersión urbana experimentados a partir de la segunda mitad del siglo XX (Chaparro, 2002).

Desde comienzos del siglo XX, y especialmente a partir de la Segunda Guerra Mundial, las redes viarias europeas de comunicación fueron acondicionadas con el fin de adaptarlas a las nuevas realidades impuestas por la cada vez mayor utilización del automóvil (Dupuy, 1998, p. 39). Por consiguiente, puede considerarse que la expansión de tales redes y la masificación del automóvil constituyen dos factores mediadores clave de la dispersión urbana, de tal modo que entre unos y otros hay una especie de relación dialéctica, pues, como dice Vester, «tráfico e infraestructura se empujan mutuamente» (Vester, 1997, p. 30-31). Para Monclús (1998, p. 5), existe una fuerte correlación entre las pautas de urbanización y los niveles de motorización y de creciente uso del coche privado. Un uso que, en gran medida, se explica por las carencias existentes en el transporte público.

El automóvil y las redes de comunicación viaria y de transporte actualmente existentes permiten vivir lejos de los centros urbanos principales, sin que ello conlleve un aumento considerable del tiempo de desplazamiento entre el lugar de residencia y el de trabajo. Pero la dispersión urbana ha sido favorecida también por la posibilidad de disponer en las zonas rurales de las mismas comodidades que ofrece la ciudad, tales como las redes de electricidad, el 
teléfono y el agua corriente (Dupuy, 1995, p. 128). Todos estos factores, unidos al creciente deterioro de las condiciones de vida en las saturadas urbes, contribuyen a que aumente el atractivo de vivir en localidades periféricas de las ciudades cada vez más alejadas del centro de ellas.

Asimismo, las presentes tendencias hacia la dispersión urbana en Europa no pueden dejar de ser relacionadas con el hecho de que las innovaciones de carácter tecnológico y organizativo hayan favorecido la localización diseminada de las actividades económicas y propiciado la aparición de unos nuevos patrones de organización y de distribución de las ciudades (Dematteis, 1998, p. 24; Monclús, 1998, p. 8). En este sentido, las posibilidades emergentes que se derivan de las nuevas tecnologías de la comunicación son importantes factores que refuerzan las tendencias hacia la expansión del modelo de ciudad difusa. Por ejemplo, la generalización de la telefonía móvil o la creciente extensión del uso de internet (Terceiro y Matías, 2001, p. 56) son dos hechos que favorecen que se produzcan cambios esenciales, en lo que se refiere a hacer posible una redefinición y compresión del espacio y del tiempo en los que las relaciones sociales se enmarcan (Giddens, 1999). De esta forma, muchas de las actividades y trámites administrativos municipales, que antes requerían necesariamente invertir tiempo en desplazarse de unos lugares espaciales a otros, ahora pueden ser realizadas simultáneamente por varias personas desde diferentes lugares que dispongan de la infraestructura necesaria para comunicarse por internet (García, 2002, p. 49). Internet permite también muchas nuevas posibilidades de comprar o trabajar desde el hogar. Esto, claro está, sólo es posible para ciertas personas con un cierto nivel cultural, profesional o socioeconómico que les permite tener acceso a dicha red.

Se están configurando, de este modo a escala planetaria, unas nuevas formas de relaciones sociales, laborales o comerciales, lo cual, además de los cambios en la organización del trabajo que conlleva, hace posible que la prestación de determinados servicios ya no requiera para ser rentable de la existencia de formas compactas de ciudad con una considerable cantidad de población, tal y como sucedía en el pasado, sino que los servicios pueden estar dirigidos desde o hacia zonas con baja densidad poblacional sin que ello suponga la elevación de los costes. Éste y otros hechos, como es el caso de las actuales tendencias que se desarrollan en ciertas ciudades hacia su descentralización administrativa, conlleva que, a menudo, en los cada vez más indefinidos y difusos espacios periurbanos europeos (análogamente a como sucede en otros espacios periurbanos del resto del mundo desarrollado), se observe la existencia de diversas localizaciones de población que pueden considerarse como una especie de centralidades periféricas, en tanto que la situación de éstas con respecto a los servicios disponibles o a las posibilidades de acceso a los mismos es equiparable a las de los centros urbanos de los que administrativamente dependen.

Pero la creciente dispersión urbana a través de aquellos espacios rurales, que están más o menos próximos a los centros de las ciudades europeas, también puede generar importantes efectos negativos o problemáticos. Entre tales 
efectos, cabe destacar una serie de ellos que se pusieron especialmente de manifiesto en el curso de las entrevistas realizadas en NEWRUR, a saber: los choques que surgen entre los usos urbanos y rurales del suelo, las fuertes transformaciones del paisaje y los perjudiciales impactos ambientales (especialmente, los relacionados con el aumento de la contaminación), las necesidades de dotar de servicios públicos apropiados a los nuevos territorios sometidos a urbanización difusa, las dificultades de tipo administrativo y fiscal que plantea la gestión de esos territorios, el aumento de los costes en infraestructuras, así como la generación y extensión de la idea de que el tipo de vivienda dispersa a que la contraurbanización da lugar es el paradigma por excelencia de calidad de vida y de bienestar, cuando esto también conlleva inconvenientes, entre los que cabe mencionar la fuerte dependencia del uso del automóvil privado, con los consiguientes problemas de congestión del tráfico y contaminación que ello genera en las ciudades y en sus áreas periurbanas.

Sin embargo, todos estos problemas no nos deben hacer olvidar que la urbanización dispersa puede tener también importantes efectos positivos, tales como la mejora de las condiciones de vida y de habitabilidad de las viviendas (Nello, 1998, p. 49), la recuperación de determinadas zonas rurales deprimidas o la utilización de algunas de ellas que no tenían un uso aparente. Asimismo, dicha urbanización puede propiciar una redistribución de las actividades económicas y de la población en el territorio que eventualmente resulte beneficiosa (Ferrás, 2000, p. 2).

En concreto, en lo que respecta a las áreas periurbanas estudiadas en profundidad en los países europeos participantes en NEWRUR, se observan notables diferencias en las causas impulsoras de los cambios socioeconómicos y problemas experimentados en ellas. Esto origina una apreciable diversidad de situaciones periurbanas en las zonas investigadas, en las que se manifiesta la coexistencia de tipos diferentes de desarrollo urbano, que, a su vez, son causa de diversas formas de complementariedad entre las zonas periurbanas y las ciudades dentro de las regiones urbanas analizadas. Las principales diferencias existentes en las zonas europeas seleccionadas pueden ser resumidas como sigue:

1. Desiguales ritmos e intensidades de crecimiento económico. Por ejemplo, especialmente intenso en El Ejido o Munich, moderado en Norwich o en situación de relativo estancamiento en Granada.

2. Diversidad en los sectores económicos, que actuan como fuerzas propulsoras del desarrollo de las áreas periurbanas y de los cambios experimentados en las mismas. Así, tales fuerzas son: en El Ejido: una agricultura moderna basada en invernaderos; en Granada: el turismo; en Munich: la industria; en Annecy: la alta tecnología o la industria tradicional, y en Norwich: las finanzas.

Por otra parte, las ciudades centrales de las áreas periurbanas estudiadas ocupan, dentro de sus respectivas regiones urbanas, un lugar destacado en lo que a la generación y concentración de los empleos se refiere. Así, en los casos de Annecy, Granada y Norwich, es en la ciudad central donde se concentran la 
mayoría de los empleos disponibles, en contraste con lo que sucede en sus respectivas áreas periurbanas, en las que en los tres casos se observa una proporción notablemente menor de oportunidades de encontrar trabajo. A diferencia de ello, Munich, al ser una ciudad mucho más grande, tiene focos de empleo de apreciable importancia en sus zonas periurbanas. No obstante, es en el centro de la ciudad y en sus cinturones suburbanos más inmediatos donde están las mayores proporciones de empleo, con lo que también se observa aquí la tendencia a la concentración del mismo en las áreas centrales manifestada en las ciudades anteriormente referidas. Por consiguiente, puede afirmarse que la característica dominante en todos los casos investigados es que en ellos el empleo está fuertemente concentrado en la ciudad central, mientras que las zonas periurbanas son espacios dedicados sobre todo a la expansión residencial. Una expansión que suele ir acompañada de una tendencia general a la disminución progresiva del empleo en la agricultura tradicional en todos los casos investigados. Disminución que está en relación con un paulatino declive de la importancia de la actividad agraria en las economías de las zonas periurbanas, lo cual está implicando una gradual reducción de la tierra dedicada al cultivo, a la vez que está cambiando las culturas locales de esas zonas, en las que los patrones de comportamiento y los estilos de vida de sus nuevos habitantes contrastan con los de sus tradicionales pobladores, generalmente con menor poder adquisitivo. Esto, además, contribuye a que, con frecuencia, aumenten las desigualdades sociales en el seno de las áreas periurbanas. Unas desigualdades que se patentizan en la existencia de estructuras sociales que presentan notables asimetrías entre la posición ocupada por las viejas clases agrarias tradicionales y las nuevas elites hegemónicas de esas áreas, cuya base económica se sustenta en actividades como los servicios o la industria, salvo en el caso de El Ejido, en el que la agricultura constituye la base económica primordial de tales elites. Sin embargo, el hecho es que la reducción de la actividad agraria y de la agricultura tradicional se está produciendo también en la zona de El Ejido, ya que el enorme crecimiento urbano experimentado en esta zona ha estado basado en un desarrollo de esa especie de agroindustria o agricultura intensiva moderna que es característica de los invernaderos, lo cual ha conllevado la virtual desaparición de la agricultura tradicional.

Un hecho común en las cuatro áreas periurbanas europeas investigadas es que en ellas el declive del empleo agrario tradicional no ha tenido como consecuencia un incremento significativo de las ocupaciones en otros sectores económicos. En general, estas áreas generan pocos empleos nuevos no relacionados con la agricultura, excepto en el turismo o en los servicios locales asociados al crecimiento poblacional. Todo ello repercute en que los centros periurbanos encuentren grandes dificultades para ampliar su rol más allá de su función como ciudades dormitorio. Como consecuencia, los viajes diarios de ida y vuelta por motivos de trabajo (commutings) se incrementan hasta unos niveles tales que amenazan la sostenibilidad del medio ambiente; sobre todo, debido a que la existencia en tales áreas periurbanas de formas de población dispersa, o agrupada en pequeños núcleos, juega en contra de la provisión de transpor- 
tes públicos, cuyos insuficientes servicios y la necesidad de recurrir al coche privado ocasionan, a menudo, enormes atascos de tráfico, ruidos y polución. Sin embargo, en Granada, en la que en general también se padecen todos estos problemas, la expansión del sector turístico ha sido un factor que ha redundado en que aumente el número de conexiones de transporte público entre la capital y algunos municipios de su área periurbana influenciados en su dinámica socioeconómica por dicho sector.

Por otra parte, en lo que respecta a las causas de la fuerte expansión residencial experimentada en las áreas periurbanas analizadas, los altos precios de las viviendas y/o la escasez de éstas en las ciudades centrales son hechos, comunes en todos los casos estudiados, que llevan a muchos a buscar otras opciones más asequibles en las referidas áreas. Búsqueda que también se ve reforzada por las crecientes demandas de viviendas unifamiliares, que son las predominantes en las zonas periurbanas. Además, la cada vez mayor demanda de segundas viviendas y la construcción de casas para el turismo son dos factores que, asimismo, influyen en el aumento de la expansión residencial, tal y como sucede, por citar dos casos de los estudiados en NEWRUR, en las regiones urbanas de Annecy (en los Alpes franceses) y de Granada.

En Alemania, y especialmente en España, el crecimiento periurbano es una consecuencia de que los propios municipios promueven la construcción de viviendas como un medio de obtener ingresos con los que aliviar sus crónicos déficits financieros, ya sea por los nuevos ingresos a través de tasas que ello les reporta, ya sea por los beneficios obtenidos mediante de la recalificación de suelos agrarios en urbanizables, lo cual se manifiesta sobre todo en el caso español.

Todo ello explica que la expansión del fenómeno de la periurbanización se esté traduciendo en un creciente aumento de las construcciones en áreas más o menos próximas a las ciudades y/o afectadas por sus influencias, lo cual tiene un notable impacto visual en tres de los cuatro países europeos implicados en NEWRUR, a saber: Alemania, Francia y España. En estos países, una serie de nuevas construcciones y de actividades, que amenazan el medioambiente, se encuentran por todas partes sin que responda su localización a un diseño urbano ni a unas medidas políticas claramente planificadas. Esto se observa incluso cuando las viviendas son de alto nivel e independientemente de cómo se desarrolle en el medio rural periurbano el proceso de extensión de tales construcciones y actividades. Así, particularmente en lo que respecta a España, tanto si dicho proceso está asociado al surgimiento y a la expansión de una agricultura intensiva de invernaderos (El Ejido), como si el mismo conlleva un gradual declive de la agricultura (Granada), en ambos casos se experimenta un deterioro de la calidad ambiental, a la vez que paradójicamente tiene lugar un aumento progresivo de la conciencia ecológica de la población (Entrena, Del Río y Rodríguez, 2003). En Alemania también el fenómeno de la creciente periurbanización conlleva una progresiva pérdida de la herencia cultural y de las prácticas rurales tradicionales. Quizá sea en Francia donde, en comparación con lo que ocurre en Alemania o en España, pueda hablarse de que los cambios en la agricultura y en el entorno derivados de dicho fenómeno se han 
producido de manera más equilibrada y sin entrañar consecuencias demasiado negativas para el medio.

En lo que se refiere al Reino Unido, hay una más clara separación entre los usos urbanos y rurales de la tierra, lo cual está relacionado con la circunstancia de que, aunque existe una considerable demanda de viviendas en zonas rurales por parte de la población (Countryside Comisión, 1997), el hecho es que la mayoría de esta demanda no puede ser satisfecha debido a las fuertes restricciones para construir en esas zonas que impone el sistema de planificación urbana vigente en tal país. Estas restricciones hacen que el número de viviendas rurales sea escaso y que, por lo tanto, para muchas familias, su precio sea a menudo más alto que el de comprar una vivienda en las ciudades. Se trata, pues, de una situación que contrasta con la existente en Francia, Alemania y España, países en los que el hecho de que la vivienda sea más barata en las áreas metropolitanas que en los centros urbanos favorece la expansión de las zonas periurbanas y aumenta la presión urbana en ellas (Henderson y Hoggart, 2003).

En cuanto al desarrollo de los servicios en las zonas periurbanas, una de las conclusiones, obtenidas en el proyecto NEWRUR, es que los modelos territoriales de provisión de servicios existentes en tales zonas no se ajustan al objetivo de distribución homogénea de los servicios, entre los pueblos y ciudades de todos los tamaños y su paisaje circundante, propugnado por el ESDP. Contrariamente a ello, los servicios tienden a concentrarse en las ciudades centrales y a decrecer en las zonas rurales. Además, si bien es verdad que el crecimiento poblacional de las áreas periurbanas ha favorecido, en la generalidad de los casos estudiados, una relativa expansión de los servicios, lo cierto es que éstos se distribuyen territorialmente de manera desequilibrada y no siempre se desarrollan en consonancia con las demandas y necesidades de la población autóctona. Por ejemplo, en las antes mencionadas zonas periurbanas de Francia o España donde se ha producido un desarrollo del turismo, resulta que muchos de los nuevos servicios que se crean están más en función de las demandas de los visitantes que las de los residentes locales, si bien es cierto que éstos también acaban por beneficiarse de los nuevos servicios, aunque no hayan sido pensados inicialmente para sus necesidades.

En definitiva, tanto cuando se analiza la periurbanización a nivel general, como cuando se la estudia a través de la investigación empírica de casos concretos, se observa que sus efectos son similares. Así, uno de los resultados más destacados del trabajo comparativo realizado es que, si bien las causas desencadenantes y/o las fuerzas propulsoras de los procesos de periurbanizacion son diversas y varían según los casos investigados en el proyecto NEWRUR (la industria, el turismo, la alta tecnología, las finanzas, etc.), lo cierto es que dichos procesos tienen consecuencias análogas en todos esos casos sobre la agricultura tradicional, el medio ambiente, la expansión de los servicios, el crecimiento residencial o el empleo. Por consiguiente, pueden plantearse estrategias políticas comunes frente a tales consecuencias y los problemas de ellas derivados. Reflexionar acerca de los retos que hoy se les plantean a esas políticas es el cometido del siguiente y último apartado de este trabajo. 


\section{Retos de las actuales políticas reguladoras de las áreas periurbanas}

Como hemos visto antes, en un contexto en el que cada vez está más extendido un modelo de ciudad difusa sin unos claros confines y estructurada en forma de red, tiende a perder sentido la tradicional dicotomía entre el campo y la ciudad. Una de las principales razones de esto es que, en el nuevo escenario de creciente globalización en el que se encuentra Europa, se produce una cada vez mayor imbricación del primero y la segunda. Como consecuencia, dejan de tener vigor las tradicionales dicotomías entre lo rural y lo urbano, a la vez que se experimenta un reemplazo de esas dicotomías por la dialéctica de lo local (rural y/o urbano) frente a lo global (Entrena, 1998, p. 178 y s.; Entrena, 2003).

En estas circunstancias, es inapropiado continuar utilizando dichas dicotomías como categorías de descripción y de análisis. Lo que en nuestros días resulta fundamental no es tanto la definición de la ciudad en abstracto como la comprensión del proceso de urbanización en una doble vertiente: por un lado, a partir del examen de las tendencias sociales que lo impulsan o son impulsadas por él, y, por otro, con el estudio de las repercusiones de ese proceso sobre el conjunto del territorio. Estas repercusiones no pueden ser adecuadamente reguladas si no se articulan proyectos colectivos de planificación urbana capaces de ordenar el desarrollo de la ciudad en beneficio de la mayoría de la población. Así, frente a los espacios urbanos ineficientes, segregados e insostenibles que se derivarían de una actuación irrestricta de los agentes privados, se precisa un diseño, un planeamiento y una estrategia colectiva. Diseño, planeamiento y estrategia que deben ser tanto sociales y económicos como ambientales y urbanísticos.

Carentes de este diseño colectivo, democráticamente definido y aplicado de acuerdo con los intereses mayoritarios, los espacios urbanos no serán ciudades. Serán, más bien, mosaicos de parcelas social y funcionalmente especializadas, yuxtapuestas sin otro principio ordenador que el de la renta urbana y el privilegio social. Conformarán así conjuntos inviables desde el punto de vista ecológico, inmanejables funcionalmente hablando y conflictivos en lo social.

Una de las mejores maneras de contribuir a crear las condiciones que eviten esto es avanzar en la línea de tender hacia una cada vez más adecuada regulación de la ordenación del territorio. Para ello, habría que plantearse objetivos como los siguientes: a) incentivar más las formas de ciudad compacta con el fin de frenar la desmesurada expansión urbana; b) reconstruir las áreas abandonadas y en ruinas, así como proporcionar acceso apropiado a los servicios y a las instalaciones básicas para todos los ciudadanos y crear más espacios abiertos y zonas verdes; c) una gestión integral de los recursos naturales, energéticos y de las basuras; d) incentivar la promoción de políticas de ordenación del territorio dirigidas a regular la localización de los usos de la tierra y a conseguir una planificación integrada del transporte público, con el propósito de reducir el uso del coche privado (European Commission, 
1999, p. 22-23). Sin embargo, el hecho es que por ahora estos objetivos distan mucho de haberse conseguido, y en las áreas urbanas lo habitual suele ser que los lugares de trabajo estén situados en puntos muy distantes de los de residencia. Como consecuencia, las interrelaciones entre los centros urbanos y sus entornos rurales y/o periurbanos son más fuertes, pero no precisamente en la forma en que requiere el ESDP, según el cual la población de tales entornos ha de tener un rol más activo en el conjunto de las áreas urbanas de las que forma parte. A diferencia de ello, lo usual es que la función de las áreas periurbanas se limiten a ser meras zonas dormitorio de los commuters que a diario viajan al centro de la ciudad y realizan allí la mayor parte de sus actividades socioeconómicas. Esto, a su vez, da lugar a una fuerte dependencia de las zonas periurbanas con respecto a los servicios que les proporciona su centro urbano, con los subsiguientes problemas de transporte y los costes ecológicos que ello suele ocasionar.

En aras de caminar hacia una cada vez más armónica ordenación territorial de las funciones, las actividades económicas y los equipamientos en las áreas periurbanas, un reto clave es dotar a tales áreas de mecanismos de gobierno democráticos, los cuales, sin destruir las identidades locales ni anular la riqueza que se deriva de las prácticas sociales en libertad, permitan planificar y gestionar unidades significativas del territorio, tales como regiones metropolitanas enteras. En tiempos de preponderancia de la ciudad difusa, es decir, cuando las dinámicas urbanas integran a todo el territorio, las administraciones públicas no deben continuar empecinándose ya en el estéril propósito de separar la ciudad de la no-ciudad, sino que su objetivo primordial ha de ser el tratar de gestionar lo más eficazmente posible unos espacios urbanos centrífugos (formados por áreas construidas y áreas abiertas, por lugares centrales y lugares periféricos o periurbanos, por sistemas generales y sistemas locales) a los que el sustrato histórico, las dinámicas sociales y la escala de las intervenciones aconsejan dotar de distintos proyectos basados en el ideal de lo que podría considerarse como la ciudad anhelada. Un ideal que, desde luego, se ha de configurar contando con los actores sociales afectados por la puesta en práctica de las políticas urbanas destinadas a su consecución. Pero, como en las realidades sociales concretas tales actores distan mucho de constituir grupos homogéneos, como entre ellos se manifiestan a menudo los intereses socioeconómicos diferentes, con frecuencia contrapuestos y eventualmente conflictivos, que existen en cualquier sociedad plural, se hace necesario crear y salvaguardar unas condiciones jurídicas, económicas, de trasparencia informativa y de respeto a los intereses generales de la población. La finalidad de ello es garantizar que sea la voluntad popular mayoritaria democráticamente expresada la que, en todo momento, determine las políticas urbanísticas a seguir. Sólo así se trabajará para evitar la posibilidad de que minorías organizadas puedan acabar desvirtuando y usurpando en su propio provecho los procesos de construcción de la ciudad, convirtiendo esa construcción y la consiguiente conformación de las áreas periurbanas en un objetivo de especulación al servicio de su particular enriquecimiento. 
En esta situación, las actuales formas de urbanización difusa están conllevando un uso extensivo del suelo que, en contraste con los tradicionales modelos de crecimiento compacto preponderantes en las ciudades continentales europeas, está contribuyendo a crear o agravar problemas, tales como la disminución de la calidad del aire, el incremento enorme de los consumos energéticos, el acrecentamiento de los ruidos o la destrucción de muchos de los tradicionales paisajes agrarios cercanos a las urbes. Todos estos problemas se caracterizan por estar fuertemente interrelacionados entre sí de forma compleja, de tal modo que el aumento de las urbanizaciones en estructura difusa lleva directamente aparejado el incremento del uso del automóvil, lo cual, a su vez, genera más ruido, dispara los consumos energéticos de contaminantes que reducen la calidad del aire y hace que se necesite cada vez más espacio para la construcción de unas vías de comunicación que fragmentan el paisaje agrario. La principal causa de todo ello es que estas urbanizaciones difusas carecen a menudo de los servicios propios de la ciudad compacta (comercio, dotaciones públicas, ocio, etc.). Al mismo tiempo, se generan zonas unifuncionales (centros comerciales, sanitarios, industriales o de ocio) junto a las grandes rutas de comunicación destinados a proporcionar servicios a toda la población del área periurbana, lo que potencia aún más la movilidad privada, no sólo entre las diferentes áreas de la periferia urbana, sino también entre éstas y la propia ciudad central.

La consideración de las consecuencias ambientales negativas que se acaban de referir plantea el reto de adoptar para los territorios periurbanos modelos de desarrollo socioeconómico, así como de planificación y de crecimiento urbanos, que tengan un carácter integral. Ello, sobre todo, porque la fuerte interrelación de los diferentes problemas que ha sido antes puesta de manifiesto haría fracasar, en mayor o menor grado, operaciones con visiones parciales o sectoriales de los problemas y las realidades existentes. No obstante, por ahora ésta no parece ser la tendencia dominante en las políticas reguladoras ni en la evolución de los procesos de periurbanización, en los que a menudo se observan una serie de hábitos de consumo inmoderados e irreflexivos, tanto de los recursos naturales como de los espacios públicos. Unos hábitos de consumo que aumentan la problemática ecológica derivada de expansión de la ciudad, al mismo tiempo que disminuyen la calidad de vida individual y colectiva, ya que estas prácticas dan lugar a incrementos desmesurados de la producción de residuos y a una degradación de recursos naturales básicos como el agua, la energía, el suelo y otras materias primas.

La participación ciudadana democrática que, en conjunción con la ineludible actuación de las administraciones públicas, se requiere para solventar estos problemas sólo puede llevarse a cabo si existen cauces institucionales y condiciones socioeconómicas que la hagan posible. Para fomentar esta participación, se necesita potenciar un sentido individual y colectivo del compromiso que fortalezca el tejido asociativo y acreciente la disposición de las personas a intervenir y a organizarse en torno a redes, de cara a ocuparse en común de sus problemas e intereses. Pero también hay que superar muchos obstáculos 
que hacen que las políticas urbanas y ambientales no tengan una efectiva aplicación y desarrollo. Por ejemplo, aunque los problemas ambientales antes mencionados no se circunscriben a las fronteras administrativas locales, regionales o nacionales, las competencias ambientales suelen estar dispersas entre multitud de organismos, áreas, secciones o departamentos. Esto entorpece mucho el desarrollo de una gestión integral del urbanismo y del medio ambiente, para cuyo logro se necesita de la coordinación entre las diferentes administraciones y niveles de éstas involucrados. Una coordinación que frecuentemente es difícil llevar a cabo, ya que, por lo general, los distintos departamentos de las administraciones públicas suelen tener una visión sectorializada de los problemas urbanísticos y ambientales que afectan a los territorios periurbanos.

En el caso español, una de las causas de la poca coordinación entre los municipios periurbanos, en lo relativo a establecer o implementar las políticas reguladoras de los procesos socioeconómicos y los problemas urbanísticos o ambientales que les afectan, es que tales municipios tienen a menudo acusadas carencias de recursos presupuestarios para hacer frente a los crecientes servicios que han de proveer a una población en constante aumento. Esto contribuye a que, con frecuencia, los municipios encuentren una forma de financiarse a través de los fondos que obtienen de las empresas constructoras al convertir suelo agrícola en urbanizable. De este modo, se explica que, en la escala local de los municipios, no siempre sean seguidas las directrices que establecen los planes urbanísticos de alcance y objetivos más globales elaborados en los niveles superiores de la Administración. Unos planes y objetivos, además, cuyos mecanismos para imponer sus directrices no son con frecuencia lo suficientemente vinculantes para los municipios, debido a que éstos suelen disponer de un amplio margen de autonomía para interpretarlos y para desarrollar sus propias reglamentaciones urbanísticas, sobre todo en los casos de España y Alemania. De ahí que el grado real de implementación de las políticas tendentes a propiciar la coordinación intermunicipal de las actuaciones urbanísticas sea a menudo débil en estos dos países. En lo que se refiere a Francia, tampoco se logra una ordenación del territorio periurbano suficientemente coordinada entre las instancias regionales y los municipios, pues éstos, lo mismo que en los otros países estudiados en NEWRUR, tienden a ir cada uno por su lado en lo que se refiere al planeamiento urbanístico. De todas formas, tanto en este país como en España, se están experimentando procesos hacia una cada vez mayor efectividad de las políticas urbanas coordinadas y establecidas en los niveles superiores de la Administración estatal o regional. Estas políticas tienen una mejor efectividad, en lo que a su aplicación se refiere, en el caso de Inglaterra, en la que las directrices del sistema de planificación nacional del territorio tienen más fuerza vinculante para los niveles inferiores de la Administración.

Frente a los problemas que presentan muchas de las actuales áreas periurbanas europeas, un reto ineludible es idear y poner en práctica de manera efectiva políticas que apuesten por soluciones integrales y por estrategias coordinadas de desarrollo sostenible. Pero el concepto de desarrollo sostenible estará 
incompleto si no se consiguen la equidad y la cohesión socioterritorial. En otras palabras, si los ciudadanos son los actores y los receptores de la sostenibilidad global, entonces buscar la sostenibilidad ambiental implica también contribuir al equilibrio socioterritorial y a mejorar los niveles de justicia y de bienestar humanos. Algo en lo que de momento todavía falta mucho por hacer, pues, como hemos podido comprobar en el curso del proyecto NEWRUR, la provisión y la distribución de los servicios en las zonas periurbanas de los países europeos analizados manifiesta aún acusadas carencias, las cuales se traducen en problemas medioambientales, de exclusión social o de ausencia de eficaces y suficientes transportes públicos.

Con objeto de superar esto y aproximarnos cada vez más a una sociedad más justa en las áreas periurbanas, hay que trabajar por la distribución equitativa de los bienes, servicios y oportunidades entre la población más desfavorecida, o sea, entre los colectivos sociales más tendentes a la exclusión social, que son los que acumulan más problemas sociales. Dichos colectivos suelen concentrarse en los barrios o áreas periurbanas más marginales y son los que sufren con más intensidad problemas como unas altas tasas de desempleo, una baja cualificación profesional, un elevado riesgo de padecer formas severas de pobreza, el analfabetismo, el residir en infraviviendas, el hacinamiento familiar, el alcoholismo, la violencia doméstica, las toxicomanías, el deterioro del mobiliario urbano y la degradación de los espacios públicos y jardines, la existencia de una escasa infraestructura administrativa, cultural, deportiva, la poca actividad comercial, etc.

Todos éstos y otros problemas exigen avanzar en las políticas de cohesión social de cara a superar la polarización estructural y socioeconómica. Uno de los objetivos prioritarios a conseguir es el desarrollo del potencial económico y la creciente diversificación funcional y social de las áreas rurales periurbanas, cuyas posibilidades en este sentido están muy vinculadas a las características socioeconómicas y a la evolución de las ciudades centrales de las que dependen. Sin embargo, además de la influencia importante que puedan ejercer esas ciudades en el desarrollo de sus zonas rurales periurbanas, un factor decisivo para tener éxito en la consecución de tal desarrollo es la elaboración y puesta en práctica de políticas adecuadas para estimular las condiciones y las ventajas sociales, ambientales y económicas que cada entorno local particular presenta (European Commission, 1999, p. 22).

Ello ocurre porque las áreas periurbanas ya no pueden seguir siendo reguladas desde planteamientos centralistas y jerárquicos. En el actual contexto, especialmente favorable para la propagación de esos modelos de ciudad difusa en forma de red aquí referidos, se hace necesario propiciar la interacción entre los actores sociales que, por activa o por pasiva, se ven implicados en los procesos de periurbanización que ello conlleva. Se trata de actuar de acuerdo con unas lógicas contractuales capaces de conectar entre sí a actores sociales pertenecientes a redes socioeconómicas diferentes. Las políticas urbanas pasarían de esta forma a ser también reticulares y conectivas, como la «ciudad sin centro» que deben gestionar. En suma, de la lógica centro-periferia, preponde- 
rante en las relaciones socioeconómicas y en las políticas urbanas hasta ahora, hay que pasar, como ya está sucediendo en diversas situaciones, a un nuevo modelo de regulación política de muchas de las urbes y de sus territorios periurbanos. Un modelo más en consonancia con las actuales tendencias hacia esas formas de ciudad sin confines que son muy difícilmente separables de un medio rural cada vez más asimilado por ellas. Tendencias que, como se ha dicho en este trabajo, están muy relacionadas con el hecho de que hayan cambiado significativamente los patrones de crecimiento poblacional y de urbanización, entendida ésta como crecimiento físico, lo cual, a su vez, está en función de varios factores, como las transformaciones en el modelo económico y productivo (el antes mencionado paso del fordismo al posfordismo), las actuales posibilidades de comunicación y de transporte o las expectativas emergentes de una gran parte de la población que anhela y/o tiende a idealizar unos lugares de residencia y estilos de vida lo más parecidos posible a los rurales.

\section{Referencias bibliográficas}

AMENDOLA, Giandomenico (1997). La città postmoderna. Magie e paure della metropoli contemporanea. Bari: Gius, Laterza \& Figli.

ARROYO, Mercedes (2001). "La contraurbanización: un debate metodológico y conceptual sobre la dinámica de las áreas metropolitanas». Scripta Nova, núm. 97. Barcelona: Universidad de Barcelona.

AsCHER, François (1995). Métapolis ou l'avenir des villes. París: Éditions Odile Jacob. Bagnasco, Arnaldo, Le Galès, Patrick (2000). Cities in Contemporary Europe. Cambridge: Cambridge University Press.

BELL, D. (1976). El advenimiento de la sociedad postindustrial. Madrid: Alianza Editorial. BERG, L. van den y otros (1982). Urban Europe. A Study of Growth and Decline. Oxford: Pergamon Press.

Berry, B. (1976). Urbanization and Counterurbanization. Beverly Hills: Sage Publications.

BRYAN, Ch. (1995). «L'Agriculture périurbaine dans la Région de Montreal: des espaces protégés mais insuffisamment valorices». Coloquio Développement urbain et conservation de la nature. París: FIHUAT, IFHP.

BUTZIN, Bernhard (1988). «Counterurbanization: spatial division of labour and regional life-cicles in Canada». Geographical perspectives, núm. 61, Salt Lake (USA): University of Utah.

CARTER, H. (1987). El estudio de la geografía urbana. Madrid: Instituto de Estudios de la Administración Local.

CASTELLS, M. (1995). La ciudad informacional. Tecnologias de la información, reestructuración económica y el proceso urbano regional. Madrid: Alianza Editorial.

- (1996). The Rise of the Network Society. Oxford: Blackwell Publishers Ltd.

- (2001). La galaxia Internet. Barcelona: Plaza \& Janés.

Chaparro Mendivelso, Jeffer (2002). «Una aproximación a la urbanización dispersa», programa de doctorado "Planificació territorial i desenvolupament regional». Asignatura: Transport i territori: anàlisi de la dimensió territorial de les polítiques de transport, impartida por el profesor Dr. Rafael Giménez i Capdevila, Departament de Geografia Física i Anàlisi Geogràfica Regional, Universitat de Barcelona. 
Countryside Commission (1997). Public Attitudes to the Countryside, Countryside Commission Postal Sales, Waldrave, Northampton.

Crecente Maseda, Rafael; Miranda Barrós, David; Cancela Barrio, Javier; MAReY PÉREZ, Manuel (2001). «Potencialidad de la ordenación parcelaria para la multifuncionalidad del espacio rural», en Actas del IV Coloquio Hispano-Portugués de Estudios Rurales sobre "La multifuncionalidad de los espacios rurales de la peninsula Ibérica». Santiago de Compostela, 7 y 8 de junio.

DematteIs, Giuseppe (1995). Progetto implicito. Il contributo delle geografia umana alle scienze del territorio. Milán: Franco Angeli.

- (1998). «Suburbanización y periurbanización. Ciudades anglosajonas y ciudades latinas», en Francisco Javier MONCLÚs (ed.). La ciudad dispersa. Barcelona: Centro de Cultura Contemporánea de Barcelona.

DupuY, Gabriel (1995). Les territoires de l'automobile. París: Anthropos.

- (1998). El urbanismo de las redes. Teorías y métodos. Barcelona: Oikos-Tau.

ENTRENA, Francisco (1998). Cambios en la construcción social de lo rural. De la autarquía a la globalización. Madrid: Tecnos.

- (2003). «From Westernization to the Whirl of Globality: Conceptualizing Globalization and Its Effects on Local Societies», en ENTRENA, Francisco (ed.) (2003). Local reactions to globalisation processes. Competitive adaptation or socio-economic erosion. Nueva York: Nova Science Publishers.

ENTRENA, F.; Río, M. DEL; RodrígueZ, N. (2003). «Characterisation of periurban, economic, social and environmental change in Granada and El Ejido", p. 97-200 de Deliverable 3.4, Review of periurbanisation processes: economic, social and spatial changes in Annecy, Valence City-Regions (France); Granada City-Region and El Ejido (Spain); Norwich City-Region (Great Britain); and Munich City-Region (Germany), Proyecto NEWRUR núm. QLK5-CT-2000-00094.

Entrena Durán, Francisco; Bertrand, Nathalie; Hoggart, Keith; Kreibich, Volker (2004). CD-ROM editado en francés, inglés, alemán y español, en el que se exponen la estructura y los resultados del proyecto europeo I + D del 5o Programa Marco sobre «Urban pressure on Rural areas: mutations and dynamics of periurban rural processes».

European Commission (1999). ESDP-European Spatial Development Perspective: Towards Balanced and Sustainable Development of the Territory of the European Union. Luxemburgo: Office for Official Publications of the European Communities.

FERRÁs, Carlos (2000). «Ciudad dispersa, aldea virtual y revolución tecnológica. Reflexión acerca de sus relaciones y significado social». Scripta Nova, núm. 69. Barcelona: Universidad de Barcelona.

Fielding, A. J. (1982). «Counterurbanization in Western Europe». Progress in Planning, núm. 17.

FONT, Antonio (1997). «Anatomía de una metrópoli discontinua: La Barcelona Metropolitana». Papers, núm. 26. Barcelona.

FreY, William H.; ZiMMER, Zachary (2001). «Defining the city», en PADDISON, Ronan (ed.). Handbook of Urban Studies. Beverly Hills: Sage Publications.

GarCía, Fernando (2002). «Trámites municipales». Ciberpaís, Diario El País (febrero). Madrid, núm. 19.

GARRIDO, Fernando (1998). «La política agroambiental europea: una primera valoración de su aplicación en España». Ponencia presentada al VI Congreso Español de Sociología, A Coruña, 24-26 de septiembre. 
GedDes, Robert (1997). «Metropolis Unbound. The Sprawling American City and the Searching for Alternatives». The American Prospect, noviembre-diciembre. GIDDENS, Anthony (1999). Consecuencias de la modernidad. Madrid: Alianza Editorial. GÓmEZ OREA, D. (1995). «Los espacios periurbanos y su planificación. La agricultura exterior y su compañía urbana. La Huerta de Valencia: recomendaciones de futuro", en Ponencias y comunicaciones del XXII Congreso Nacional de Parques y Jardines, PARJAP 95. Valencia: Ayuntamiento de Valencia.

Henderson, Steven; HogGarT, Keith (2003). «Comparative analysis of development-process characterisation in periurban areas in the European Union», 29 páginas, Deliverable 3.5. Proyecto NEWRUR núm. QLK5-CT-2000-00094. Londres: Department of Geography, King's College.

HERNÁNDEZ MonTESINOS, María Isabel (2001). «Estudio de las dinámicas agrarias y de las estrategias de los agricultores en medio periurbano", en Actas del IV Coloquio Hispano-Portugués de Estudios Rurales sobre "La multifuncionalidad de los espacios rurales de la peninsula Ibérica». Santiago de Compostela, 7 y 8 de junio.

Indovina, F. (ed.) (1990). La cittá difusa. Venecia: Daest.

IZCARA PAlacios, Simón Pedro (1999). «El deficit de implementación de las directivas medioambientales de la Unión Europea». Revista Internacional de Sociología, núm. 24.

Lever, W. F. (2001). «The Post-fordist City», en PAdDison, Ronan (ed.). Handbook of Urban Studies. Beverly Hills: Sage Publications.

López González, Francisco Javier; Crecente Maseda, Rafael; Fra Paleo, Urbano (2001). «El aspecto territorial y la correcta delimitación de las zonas de actuación como claves para el desarrollo rural y la aplicación de las iniciativas comunitarias", en Actas del IV Coloquio Hispano-Portugués de Estudios Rurales sobre "La multifuncionalidad de los espacios rurales de la peninsula Ibérica», Santiago de Compostela, 7 y 8 de junio.

MONCLÚS, Francisco Javier (1998). «Suburbanización y nuevas periferias. Perspectivas geográfico-urbanísticas», en MONCLÚs, Francisco Javier (ed.). La ciudad dispersa. Barcelona: Centro de Cultura Contemporánea de Barcelona.

Nello, Oriol (1998). «Los confines de la ciudad sin confines. Estructura urbana y límites administrativos en la ciudad difusa», en Monclús, Francisco Javier (ed.). La ciudad dispersa. Barcelona: Centro de Cultura Contemporánea de Barcelona. PANIAGUA, Ángel (1997). «Significación social e implicaciones para la política agraria de la "cuestión ambiental" en el medio rural español», en GÓMEZ BENITO y GONZÁlEZ RODRíGUEZ (eds.). Agricultura y sociedad en la España contemporánea. Madrid: Ministerio de Agricultura, Pesca y Alimentación / Centro de Investigaciones Sociológicas (CIS).

Pellicer Corellano, Francisco (1998). «El ciclo del agua y la reconversión del paisaje periurbano en las ciudades de la Red C-6 ${ }^{4}$ ", en MONCLÚs, Francisco Javier (ed.). La ciudad dispersa. Barcelona: Centro de Cultura Contemporánea de Barcelona. Precedo Ledo, A. (1988). La red urbana. Madrid: Síntesis.

- (1996). Ciudad y desarrollo urbano. Madrid: Síntesis.

SÁNCHEZ, Joan-Eugeni (1998). «Transformaciones en los sistemas productivos y expansión metropolitana», en MONCLÚs, Francisco Javier (ed.). La ciudad dispersa. Barcelona: Centro de Cultura Contemporánea de Barcelona.

4. Esta red está integrada por Barcelona, Montpellier, Palma de Mallorca, Toulouse, Valencia y Zaragoza. 
SANCHO MARTí, J. (1989). «El espacio periurbano de Zaragoza». Cuadernos de Zaragoza, núm. 59. Zaragoza: Ayuntamiento de Zaragoza, 2 volúmenes.

Sassen, S. (1991). Global city: New York, Londres and Tokyo. Princeton, NJ: Princeton University Press.

Sevilla-GuZMÁn, Eduardo; López Calvo, Araceli (1993). «Agroecología y campesinado: reflexiones teóricas sobre las ciencias agrarias ante la crisis ecológica", ponencia presentada a las Jornadas de Historia Agraria, abril de 1993, Almería. SoJA, Edward W. (2000). Postmetropolis. Critical Studies of Cities and Regions. Oxford, UK: Blackwell Publishers.

Terceiro, José; MATías, Gustavo (2001). Digitalismo. El nuevo horizonte sociocultural. Madrid: Taurusesdigital.

TOURAINE, A. (1980). El postsocialismo. Barcelona: Planeta.

VESTER, Frederic (1997). El futuro del tráfico. Barcelona: Flor del Viento Ediciones. ZÁrATE, A. (1984). El mosaico urbano: organización interna y vida en las ciudades. Madrid: Cincel. Cuadernos de Estudio. Geografía. 